\title{
Methionine synthesis in Proteus mirabilis
}

\author{
By W. O. K. GRABOW AND J. A. SMIT \\ Department of Microbiology, University of Pretoria, and \\ Atomic Energy Board, Pretoria, South Africa
}

(Accepted for publication 8 August 1966)

\begin{abstract}
SUMMARY
Sixty different isolates of methionineless auxotrophs of Proteus mirabilis were arranged in nine biochemical groups according to their growth responses to methionine or its precursors. These requirements suggested that $P$. mirabilis possesses a route for methionine biosynthesis which is similar to the pathway operating in Escherichia coli and Salmonella typhimurium. In contrast to findings with the latter organisms syntrophism was not observed between these mutants of $P$. mirabilis even with sonically disrupted potential feeder strains. Two methionineless auxotrophs of $E$. coli fed auxotrophs of $P$. mirabilis which had metabolic blocks earlier in this pathway. These results, which suggested an inability of methionineless auxotrophs of $P$. mirabilis to accumulate precursors of metabolic blocks, were confirmed by a quantitative comparison of methionine precursors in wild-type and mutant strains of $P$. mirabilis and $E$. coli. The presence of $S$-methylcysteine (SMC) was demonstrated in wild-type and methionineless auxotrophs of $P$. mirabilis and $E$. coli. The growth responses of methionineless auxotrophs of $P$. mirabilis to SMC supported a hypothesis for the participation of this amino acid in the synthesis of methionine via an alternative route.
\end{abstract}

\section{INTRODUCTION}

Syntrophism amongst methionineless auxotrophs of bacteria has been used to study the sequence of intermediates in the synthesis of methionine. The reports of Lampen, Roepke \& Jones (1947) and of Davis \& Mingioli (1950) dealt with such mutants of Escherichia coli; syntrophism occurred between auxotrophs with different nutrient requirements. Demerec et al. (1955) and Smith (1961) demonstrated syntrophism amongst different phenotypic groups of methionineless auxotrophs of Salmonella typhimurium. Clowes (1958) reported syntrophism among cysteineless mutants of $S$. typhimurium. Figure $1 a$ represents the pathway of methionine formation by micro-organisms as revealed by the syntrophism tests of the above workers. It proceeds via cysteine and $O$-succinylhomoserine to form cystathionine, which is cleaved to homocysteine and then methylated to methionine. A second pathway was demonstrated by Wiebers \& Garner (1963) who isolated from Neurospora crassa an enzyme which was capable of forming homocysteine from homoserine and $\mathrm{H}_{2} \mathrm{~S}$. Ragland \& Liverman (1956) suggested a third route, namely a transthiomethylation of the thiomethyl group of $S$-methylcysteine (SMC) to homoserine to yield methionine (Fig. $1 b$ ). These authors isolated SMC from extracts of $N$. crassa and reported that SMC could serve as sole sulphur source for certain strains. The results of Wiebers \& Garner (1964) indicated the participation of SMC in the biosynthesis of methionine in 
$N$. crassa by a pathway which excludes cysteine. The same may be true for yeasts (Maw, 1961). Wolff, Black \& Downey (1956) showed the synthesis of SMC in bakers yeast. Roberts et al. (1955) reported that SMC could be utilized by E. coli in isotope competition experiments and also by a cysteine-requiring mutant of this organism.

The present paper deals with the pathway for methionine synthesis in Proteus mirabilis, the absence of syntrophism among methionineless mutants of $P$. mirabilis and the presence, in $P$. mirabilis and in Escherichia coli, of $S$-methylcysteine which had not previously been shown to occur in bacteria.

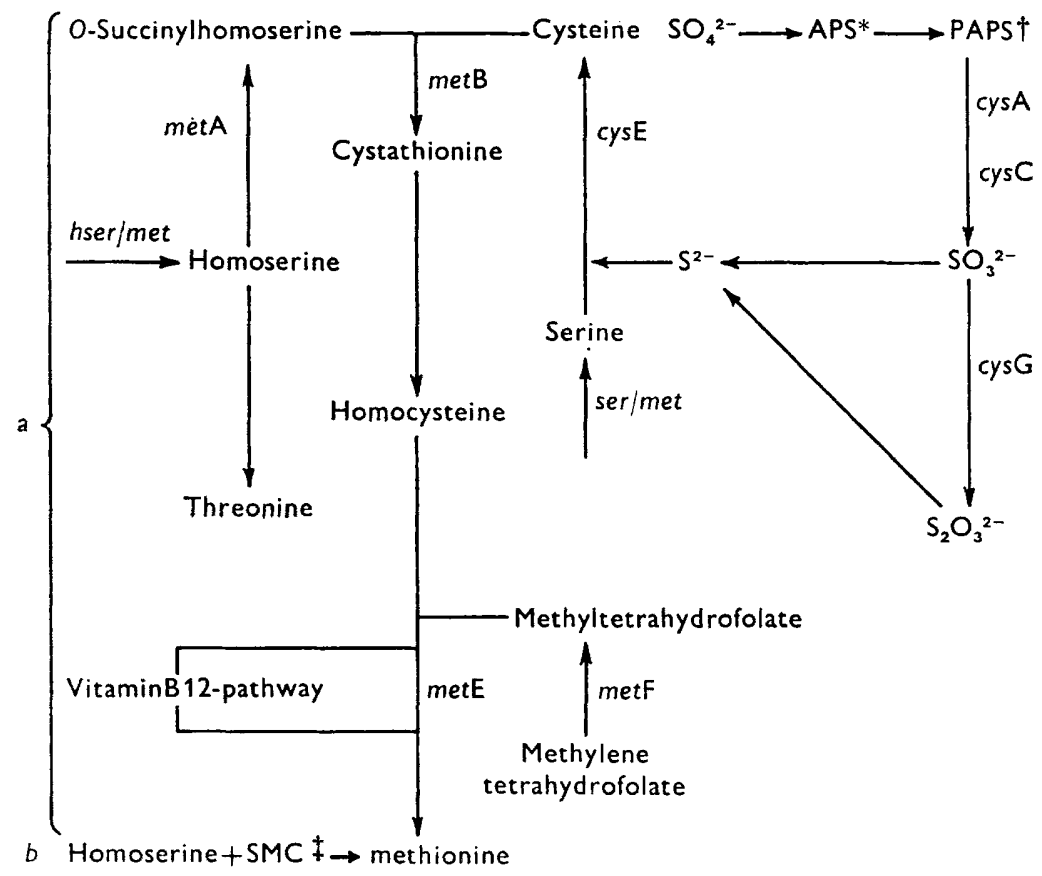

Fig. 1. Two possible pathways of methionine synthesis. $a$, Classical pathway; $b$, alternate pathway. * Adenosine-5'-sulphatophosphate; $†$ 3'-phospho-adenosine-5'-sulphatophosphate; $\ddagger S$-methylcysteine. metF, cys $\mathrm{E}$, hser/met, etc., indicate metabolic blocks.

\section{METHODS}

Media. The minimal medium was a modification of that of Davis \& Mingioli (1950) (g./1.): $\mathrm{K}_{2} \mathrm{HPO}_{4}, 10.5 ; \mathrm{KH}_{2} \mathrm{PO}_{4}, 4.5 ; \mathrm{Na}_{3}$-citrate. $2 \mathrm{H}_{2} \mathrm{O}, 0.47 ;\left(\mathrm{NH}_{4}\right)_{2} \mathrm{SO}_{4}, 1.0$; $\mathrm{MgSO}_{4} \cdot 7 \mathrm{H}_{2} \mathrm{O}, 0 \cdot 102$; glucose (autoclaved separately), 2.5; agar $17 \cdot 5$; distilled water 11. The $\mathrm{pH}$ of this medium was 7.2. For the growth of Proteus mirabilis strains nicotinic acid $(7 \cdot 5 \mu \mathrm{g} . / \mathrm{ml}$., membrane filtered) was added. Top-layer agar contained $0.7 \%(\mathrm{w} / \mathrm{v})$ agar. The sulphur-free medium had $\left(\mathrm{NH}_{4}\right)_{2} \mathrm{SO}_{4}$ and $\mathrm{MgSO}_{4} \cdot 7 \mathrm{H}_{2} \mathrm{O}$ replaced by equivalent amounts of $\mathrm{NH}_{4} \mathrm{Cl}$ and $\mathrm{MgCl}_{2} \cdot 6 \mathrm{H}_{2} \mathrm{O}$, respectively.

Chemicals. Carrier-free ${ }^{35} \mathrm{~S}$-sulphate in aqueous solution (pH 6.5-7.5) was obtained from the Radiochemical Centre, Amersham, Buckinghamshire, England, and amino acids from the Nutritional Biochemicals Corporation, Cleveland, Ohio, U.S.A. Analytical grade sulphate, sulphite, thiosulphate and sulphide were used to test growth responses to inorganic precursors of cysteine (Postgate, 1963). 
Organisms. Mutants of Proteus mirabilis strain 13 (Coetzee \& Sacks, 1960) were obtained by treatment with ultraviolet radiation, manganese chloride or hydrogen peroxide (Demerec, Bertani \& Flint, 1951). The penicillin method of Lederberg \& Zinder (1948) and Davis (1948) was used to select auxotrophic mutants which were isolated by the replica-plating technique of Lederberg \& Lederberg (1952). For the isolation of methionineless mutants of Escherichia coli strain CA-7 (obtained from Professor Fredericq, Liège) the more selective method of Gorini \& Kaufman (1960) was used. The nutritional requirements of mutants were determined auxanographically (Lederberg, 1946); sulphur sources were applied in drops containing $3 \mathrm{mg}$. S/ml. The abbreviations $m e t \mathrm{~F}, c y s \mathrm{E}$, hser/met, etc., are used to indicate specific metabolic blocks in the methionine pathway (Sanderson \& Demerec, 1965) as shown in Fig. 1 and correspond to the growth requirements listed in Table 1. Organisms were maintained on nutrient agar slopes at $4^{\circ}$.

Disruption of organisms. Extracts of organisms were prepared from suspensions ( $30 \mathrm{ml}$; ; equiv. $500 \mathrm{mg}$. dry wt. bacteria) by ultrasonic treatment in a Raytheon model $\mathrm{S} 102 \mathrm{~A}$ oscilator $(9 \mathrm{kcyc}$./sec. for $2 \mathrm{hr}$ ).

Syntrophism. This was determined by the following techniques. (a) Parallel streaking (Demerec et al. 1955; Smith, 1961; Clowes, 1958). Parallel streaks of mutants were made about 2-3 mm. apart on minimal medium enriched with either methionine $(2 \mu \mathrm{g} . / \mathrm{ml}$.) or $0.2 \%$ (w/v) Difco nutrient broth powder. (b) Auxanographic technique (Clowes, 1958). Liquid cultures of organisms grown with limiting amounts of methionine $(2 \mu \mathrm{g} . / \mathrm{ml}$.) were centrifuged down and the supernatant fluids and the deposits (after ultrasonic treatment) were tested auxanographically for their ability to support growth of other mutants. Testing of disrupted cell material for feeding ability eliminated the possible impermeability of feeding strains for accumulated metabolites. (c) Replica plating (Smith, 1961). Inocula of 6 methionineless mutants were spread over well-separated areas of about $1 \mathrm{~cm}$. diameter on each of a number of Difco SS agar plates (Difco MacConkey agar for Escherichia coli), over a template. After overnight incubation these plates were replicated (Lederberg \& Lederberg, 1952) to single enriched minimal medium plates on which different methionineless auxotrophs were spread. Syntrophism was evident as haloes of growth round replicated areas. (d) Turbidimetric technique (Lampen et al. 1947; Davis \& Mingioli, 1950). Overnight broth cultures of test strains were washed twice with saline and resuspended in the original volume of saline. Tubes containing $40 \mathrm{ml}$. enriched minimal medium were inoculated separately with $0.5 \mathrm{ml}$. of these washed suspensions. Similar tubes were inoculated with $0.25 \mathrm{ml}$. of washed suspensions of each of two different strains to yield a total inoculum volume of $0.5 \mathrm{ml}$., analogous to that of tubes with single inoculun. After $24 \mathrm{hr}$ incubation the turbidity of cultures was compared. Syntrophism was indicated by mixed inocula yielding heavier growth than single inocula. (e) Colonial syntrophism (Demerec et al. 1955). Pairs of mutants were plated in proportions so that one would form a background growth on the surface of slightly enriched minimal medium and might feed the small number of organisms of the other mutant present in the mixture. Apart from the turbidimetric technique, syntrophism experiments were observed for at least 7 days. Incubation temperature was $37^{\circ}$.

Isolation of free amino acids. Strains were grown for $20 \mathrm{hr}$ on a sulphur-free medium supplemented with ${ }^{35} \mathrm{~S}$-sulphate $(0.5 \mu \mathrm{c}$./ $\mathrm{ml}$.) as the sole sulphur source. For methionineless mutants the medium was enriched with DL-methionine $(7 \mu \mathrm{g} . / \mathrm{ml}$.). After 
$20 \mathrm{hr}$ incubation, by which time all free sulphur-containing amino acids would be metabolized and replaced by intermediates containing the isotope (Cowie, Bolton \& Sands, 1950; Roberts et al. 1955) the organisms were harvested and a $30 \mathrm{ml}$. suspension (equiv. $500 \mathrm{mg}$. dry wt. bacteria) prepared in distilled water. Bacterial concentrations were also estimated by measuring the extinction at $630 \mathrm{~m} \mu\left(E_{630}\right)$ and by determination of the protein content of disrupted extracts by the biuret method of Gornall, Bardawill \& David (1949) with bovine albumin as standard. Disrupted cell material was centrifuged at $151,000 \mathrm{~g}$ in a Spinco Model $\mathrm{L}$ ultracentrifuge for $30 \mathrm{~min}$. Proteins and peptides in the supernatant fluid were precipitated with a final concentration of $10 \%$ perchloric acid and centrifuged. The supernatant fluid was neutralized with $5 \mathrm{~N}-\mathrm{KOH}$ followed by centrifugation and filtration. The filtrate was passed through a column $\left(25 \times 1 \mathrm{~cm}\right.$.) of cation exchange resin (Amberlite IR 120, $\mathrm{H}^{+}$form) followed by $100 \mathrm{ml}$. water to remove carbohydrates, salts, inorganic sulphur precursors of cysteine and excess ${ }^{35} \mathrm{~S}$-sulphate. The amino acids were then eluted with $\mathrm{N}-\mathrm{NH}_{4} \mathrm{OH}(50 \mathrm{ml}$.), concentrated to dryness under vacuum and one half of the material oxidized with performic acid (Leggett Bailey, 1962; Moore, 1963). Unoxidized sulphur-containing amino acids possess different $\boldsymbol{R}_{\boldsymbol{F}}$ values than the oxidized derivatives, and experiments were done with both types of preparation (Wiebers \& Garner, 1964; Roberts et al. 1955).

Chromatography of amino acid mixtures. Two-dimensional chromatograms on Whatman no. $3 \mathrm{MM}$ paper were developed for $16 \mathrm{hr}$ by the descending technique. The solvents used were: first dimension, $n$-butanol + formic acid + water $(77+10+13$, by vol.); second dimension, $n$-butanol + pyridine + water $(1+1+1$, by vol.). Amino acids were located by dipping into $0.2 \%(\mathrm{w} / \mathrm{v})$ ninhydrin in acetone and heating at $100^{\circ}$ for $5 \mathrm{~min}$. The identity of amino acids was confirmed by paper electrophoresis, thin-layer chromatography and auxanography, using samples eluted from uncoloured chromatograms. Paper electrophoresis was done on Whatman no. $3 \mathrm{MM}$ paper with a $\mathrm{pH} 1.85$ buffer consisting of $2 \cdot 5 \%(\mathrm{v} / \mathrm{v})$ formic acid $+7 \cdot 8 \%(\mathrm{v} / \mathrm{v})$ acetic acid (Leggett Bailey, 1962). Thin-layer chromatography was done on activated silica-gel $G$ layers according to Randerath (1964). For auxanographic identification drops of eluates from paper chromatograms were spotted on minimal medium plates seeded with auxotrophs with known nutrient requirements in top layers. Positive results were obtained after $24-48 \mathrm{hr}$ incubation.

Quantitative comparison of sulphur-containing amino acids. The radio-activity of the sulphur-containing amino acids was determined by counting rectangular pieces $(0.5 \times 2.0 \mathrm{~cm}$.) of the two-dimensional chromatograms in a Packard Model 3003 tricarb liquid scintillation spectrometer. The efficiency of the counter for ${ }^{35} \mathrm{~S}$ was $62 \%$ and sufficient counts were recorded to give a statistical error of less than $2 \%$. Counts were corrected for isotopic decay. The scintillation fluid was $0.4 \%(\mathrm{w} / \mathrm{v})$ p-terphenyl $+0.04 \%$ (w/v) 1,4-bis-(4-methyl-5-phenyloxazol-2-yl)-benzene in toluene, +1,4-dioxane $(7+3$, by vol.). Similar determinations were carried out after separation and identification by paper electrophoresis. The radioactivity of the sulphur-containing amino acids/mg. dry wt. organisms grown on ${ }^{35} \mathrm{~S}$-sulphate was used as standard for comparison of the amounts of these amino acids in mutant and wild-type strains of Proteus mirabilis and Escherichia coli. These estimates are minimal since no attempt was made to compensate for excretion of accumulated metabolites during growth or losses during isolation and chromatography. 


\section{RESULTS}

Methionineless auxotrophs. Fifty-two isolation experiments yielded 2066 auxotrophic strains of Proteus mirabilis of which the largest group, 380, required methionine for growth; of these, auxotrophs responding to cysteine were especially abundant. These findings are analogous to those of Horowitz (1955) with mutants of Neurospora crassa. About $50 \%$ of our methionineless proteus auxotrophs were leaky. A final group of 60 auxotrophs was chosen on the basis of one phenotypically distinguishable type per isolation experiment. Mutant ser/met-544 was leaky but is included as the only representative of its type. The growth responses shown in Table 1 indicate that these

\section{Table 1. Grouping and growth requirements of methionineless auxotrophs of Proteus mirabilis}

Growth requirements were determined by applying possible precursors in drops of appropriate concentration on minimal medium containing auxotrophs in a top layer.

Growth requirements

\begin{tabular}{|c|c|c|c|c|c|c|c|c|c|c|}
\hline $\begin{array}{l}\text { Auxotroph } \\
\text { group }\end{array}$ & $\mathrm{SO}_{3}{ }^{2-}$ & $\mathrm{S}_{2} \mathrm{O}_{3}{ }^{2-}$ & $\mathbf{S}^{2-}$ & Ser & Cys & Hser & Cyst & Hcys & B12 & Met \\
\hline met $\mathrm{F}$ & - & - & - & - & - & - & - & - & - & + \\
\hline met $\mathrm{E}$ & - & - & - & - & - & - & - & - & + & + \\
\hline$m e t \mathrm{~A} / \mathrm{B}$ & - & - & - & - & - & - & + & + & - & + \\
\hline hser/met & - & - & - & - & - & $t$ & + & + & - & + \\
\hline cys $\mathrm{E}$ & - & - & - & - & + & - & + & + & - & + \\
\hline ser/met & - & - & - & + & + & - & + & + & - & + \\
\hline cys $\mathrm{G}$ & - & + & + & - & + & - & + & + & - & + \\
\hline cys $\mathrm{C}$ & + & + & + & - & + & - & + & + & - & + \\
\hline$c y s \mathrm{~A}$ & + & - & + & - & + & - & + & + & - & + \\
\hline
\end{tabular}

Cys, Cysteine; Cyst, cystathionine; Hcys, homocysteine; Hser, homoserine; Met, methionine; Ser, serine; B12, vitamin B12; +, growth equivalent to that with methionine as supplement; -, no growth.

Table 2. Methionineless strains of Proteus mirabilis

Auxotrophic mutants were obtained by treatment of the wild-type strain with mutagenic agents, selected with penicillin and isolated by replica-plating. Sixty auxotrophs were chosen on the basis of one phenotypically distinguishable type per isolation experiment.

The growth requirements for each group are listed in Table 1.

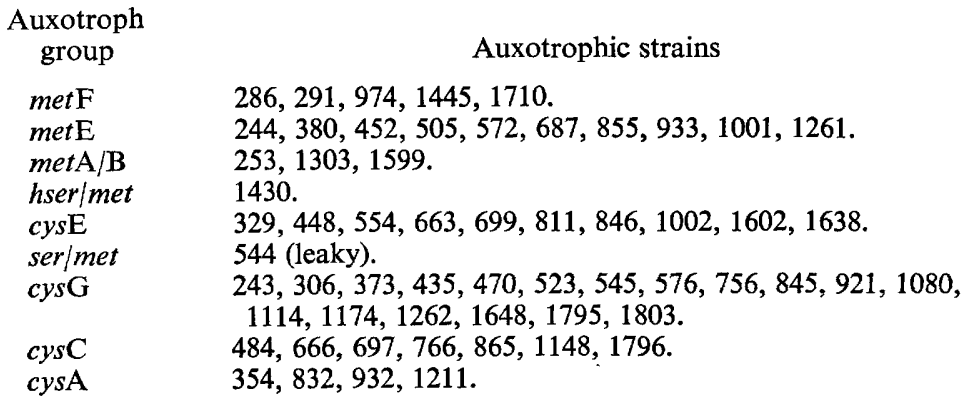

mutants could be separated into nine biochemical groups. The nomenclature of each group corresponds to the metabolic block indicated in Fig. 1. Auxotrophs responding to methionine, homocysteine, cystathionine or homoserine are referred to as hser/met 
(Table 2). It is not known where the metabolic block in the homoserine pathway is since the growth response of these mutants to possible precursors of homoserine was not tested. The same holds for the ser/met mutant which responds to methionine, homocysteine, cystathionine, cysteine or serine (Table 2). The strains of $P$. mirabilis used in these experiments will be referred to as methionineless strains and they are listed in Table 2. All the auxotrophs in Table 2 except hser/met-1430 and ser/met-544, when supplemented with $S$-methylcysteine(SMC)in minimal medium, show growth equivalent to that with methionine. The two exceptions grew very poorly with SMC. Prototrophic strains of $P$. mirabilis and Escherichia coli utilized SMC as the only source of sulphur in accordance with the findings of Roberts et al. (1955) with E. coli. Proteus mirabilis $m e t \mathrm{E}-1001$ was classified as met $\mathrm{E}$ because it responded either to methionine or to vitamin B 12 but not to homocysteine. However, this mutant was also found to grow when supplemented with threonine. The growth response of the auxotrophs to the possible intermediate $O$-succinyl-homoserine (Rowbury, 1964) was not tested and consequently met $\mathrm{A}$ and met $\mathrm{B}$ mutants were classed together in group met $\mathrm{A} / \mathrm{B}$ which responded, to cystathionine, homocysteine or methionine. All met $\mathrm{E}$ auxotrophs, except met $\mathrm{E}-505$, attained complete growth after $24 \mathrm{hr}$ when supplemented with vitamin B 12. MetE-505 was fully grown, with vitamin B 12, only after $48 \mathrm{hr}$. When supplemented with methionine the metE mutants like all methionine auxotrophs showed full growth after $24 \mathrm{hr}$. This difference in response to vitamin B 12 was also noted by Davis \& Mingioli (1950) with similar mutants of $E$. coli.

Two methionine-requiring auxotrophs of Escherichia coli strain CA-7 were isolated and designated metF-1, -2 . In minimal medium these mutants responded only to methionine and, in contrast to the met $\mathrm{F}$ mutants of $P$. mirabilis, did not grow with SMC.

Syntrophism among methionineless mutants of Proteus mirabilis and Escherichia coli. All syntrophism techniques gave positive results with several biochemically different arginine-requiring mutants of $P$. mirabilis (Coetzee, 1965). These experiments served as controls for the syntrophism techniques used. No syntrophism was detected between pairs of methionineless mutants of $P$. mirabilis. The only exception was metE-1001 which was fed by all the methionineless mutants of $P$. mirabilis and by the two metF auxotrophs of $E$. coli. These methionineless strains of $P$. mirabilis and the two metF mutants of $E$. coli also fed both threonine-requiring and glycine-requiring mutants of $P$. mirabilis, and it is possible that the ability to feed metE-1001 may be due to this mutant's growth response to threonine. This behaviour of metE-1001 was not further investigated.

The absence of syntrophism among methionineless auxotrophs of Proteus mirabilis pointed to an inability of these mutants to accumulate the precursors of metabolic blocks in a methionine pathway. Since syntrophism is known to occur among methionine-requiring auxotrophs of Escherichia coli (Lampen et al. 1947; Davis \& Mingioli, 1950) the two met $F$ mutants of this organism were tested for their ability to feed methionineless mutants of $P$. mirabilis. Met $\mathrm{F}$ mutants of $E$. coli fed all the methionineless mutants of $P$. mirabilis except those of groups met $\mathrm{F}$ and met $\mathrm{E}$.

Quantitative comparison of sulphur-containing amino acids in wild-type and methionineless auxotrophs of Proteus mirabilis and Escherichia coli. The estimates of sulphurcontaining precursors of methionine in wild-type and some methionineless auxotrophs of $P$. mirabilis and $E$. coli are listed in Table 3. These quantitative estimates confirmed 
the results of syntrophism tests. Although metF-1710 and metE-855 contain about three times as much homocysteine and metA/B-1599 contains almost twice as much cysteine as the wild-type organism, this small accumulation of precursors of metabolic blocks is possibly not enough to produce syntrophism. In contrast, $E$. coli met $\mathrm{F}-1$ contained about forty times as much homocysteine and more than thirty times the cystathionine content of the wild-type strain. Similar results were obtained with all representatives of each group of $P$. mirabilis mutants. As would be expected from its early block, $P$. mirabilis cysC-697 only contained traces of sulphur-containing precursors of methionine.

Table 3. Sulphur-content of amino-acid precursors of methionine in wild-type and methionineless auxotrophs of Proteus mirabilis and Escherichia coli

Organisms were grown on sulphur-free medium containing limiting amounts of ${ }^{35} \mathrm{~S}-$ sulphate as sole sulphur source, harvested after $20 \mathrm{hr}$ and sonically disrupted. Free amino acids from equivalent amounts of organisms (equiv. $500 \mathrm{mg}$. dry wt.) were isolated and separated by paper chromatography. The radioactivity of each amino acid/mg. dry wt. bacteria was taken as quantitative standard of comparison. Counts were corrected for isotopic decay which ranged between 9 and $22 \%$ when the measurements were made.

\begin{tabular}{|c|c|c|c|c|c|c|}
\hline \multirow{2}{*}{ Organism } & \multicolumn{5}{|c|}{ Sulphur source } & \multirow[b]{2}{*}{$\begin{array}{c}\text { Total } \\
\text { activity }\end{array}$} \\
\hline & Methionine & $\begin{array}{l}\text { Homo- } \\
\text { cysteine } \\
\text { Radioactivit }\end{array}$ & $\begin{array}{l}\text { Cysta- } \\
\text { thionine } \\
\text { (counts } / \mathrm{m}\end{array}$ & $\begin{array}{l}\text { Cysteine } \\
\text { in./mg. dry }\end{array}$ & $\begin{array}{c}\text { SMC* } \\
\text { wt. bacteria) }\end{array}$ & \\
\hline $\begin{array}{l}\text { Escherichia coli } \\
\text { Wild type } \\
\text { met } \mathrm{F}-1\end{array}$ & $\begin{array}{r}136 \cdot 0 \\
5 \cdot 8\end{array}$ & $\begin{array}{r}124 \cdot 0 \\
5800 \cdot 0\end{array}$ & $\begin{array}{r}96 \cdot 0 \\
3600 \cdot 0\end{array}$ & $\begin{array}{l}128 \cdot 0 \\
246 \cdot 0\end{array}$ & $\begin{array}{r}118 \cdot 0 \\
4400 \cdot 0\end{array}$ & $\begin{array}{r}602 \cdot 0 \\
14051 \cdot 8\end{array}$ \\
\hline $\begin{array}{l}\text { Proteus mirabilis } \\
\text { Wild type } \\
\text { met } \mathrm{F}-1710 \\
\text { met } \mathrm{E}-855 \\
\text { met } \mathrm{A} / \mathrm{B}-1599 \\
\text { cys } \mathrm{C}-697\end{array}$ & $\begin{array}{r}124 \cdot 0 \\
4 \cdot 2 \\
3 \cdot 6 \\
3 \cdot 8 \\
4 \cdot 0\end{array}$ & $\begin{array}{r}106 \cdot 0 \\
302 \cdot 0 \\
294.0 \\
3.4 \\
3.6\end{array}$ & $\begin{array}{r}90 \cdot 0 \\
196.0 \\
192 \cdot 0 \\
2 \cdot 8 \\
3.0\end{array}$ & $\begin{array}{r}122.0 \\
166.0 \\
158.0 \\
214.0 \\
3.8\end{array}$ & $\begin{array}{r}102 \cdot 0 \\
3 \cdot 8 \\
3 \cdot 8 \\
4 \cdot 2 \\
3 \cdot 2\end{array}$ & $\begin{array}{r}544 \cdot 0 \\
672 \cdot 0 \\
651 \cdot 4 \\
228 \cdot 2 \\
17 \cdot 6\end{array}$ \\
\hline
\end{tabular}

The chromatographic studies of methionine precursors led to the discovery of $S$-methylcysteine (SMC) in wild-type and mutant strains of Proteus mirabilis and Escherichia coli (Table 3). The identity of SMC was confirmed by two-dimensional paper chromatography, paper electrophoresis and thin-layer chromatography of oxidized and unoxidized samples of amino acids isolated from these organisms. SMC isolated from strains grown on ${ }^{35} \mathrm{~S}$-sulphate as sole sulphur source contained the ${ }^{35} \mathrm{~S}$ isotope. Mutant strains of $P$. mirabilis which attained growth equivalent to that with methionine when supplemented with SMC contained negligible amounts of SMC themselves. The two met $\mathrm{F}$ mutants of $E$. coli which did not respond to SMC accumulated SMC in large quantities (Table 3); this suggested that they should feed $m e t \mathrm{~F}$ and met $\mathrm{E}$ mutants of $P$. mirabilis which do respond to SMC. However, no such syntrophism was observed. 


\section{DISCUSSION}

The growth requirements of the methionineless auxotrophs of Proteus mirabilis (Table 1) indicate that the route of methionine synthesis (Fig. $1 a$ ) is similar to that found in Escherichia coli, Salmonella typhimurium and Neurospora crassa (Meister, 1965; Cauthen, Foster \& Woods, 1966). The absence of syntrophism between methionineless auxotrophs of $\boldsymbol{P}$. mirabilis contrasts sharply with similar mutants of $E$. coli and $S$. typhimurium. According to growth requirements the met $\mathrm{F}$, met $\mathrm{E}$ and metA/B mutants of $P$. mirabilis appear to be similar to auxotrophs of $S$. typhimurium with which Smith (1961) and Demerec et al. (1955) obtained syntrophism. Clowes (1958) showed cross-feeding with cysteineless mutants cys $\mathrm{D}$, cys $\mathrm{C}$, cys $\mathrm{E}$ and cys $\mathrm{A}$ of $S$. typhimurium whose growth requirements are much the same as the cys $\mathrm{G}$, cys $\mathrm{C}$, cysE and cys A mutants of $P$. mirabilis. Lampen et al. (1947) and Davis \& Mingioli (1950) reported syntrophism between several methionineless strains of $E$. coli with similar blocks to the $P$. mirabilis strains studied here. The absence of syntrophism caused by impermeability of the cell membranes to intermediates in methionine synthesis was ruled out, furthermore the syntrophism techniques appeared to be reliable and all previous studies on methionine metabolism have indicated that these intermediates are stable. The explanation for this behaviour appears to lie in the inability of $P$. mirabilis mutants to accumulate sufficient quantities of methionine precursors to produce syntrophism. Evidence for this possibility was contributed by the finding that methionineless auxotrophs and wild-type strains of $P$. mirabilis contained equivalent amounts of methionine precursors. In contrast, a met $\mathrm{F}$ mutant of $E$. coli contained more than twenty times the methionine precursors than the wild-type strain.

The observation that all our mutants which require cysteine, homoserine and serine respond to methionine is noteworthy. This may mean that the methioninecysteine pathway is reversible in Proteus mirabilis and that methionine can serve as a precursor for these amino acids. However, cysteineless mutants of Escherichia coli (Lampen et al. 1947) and Salmonella typhimurium (Demerec et al. 1955) were also found to respond to methionine although the pathway is unidirectional in these organisms (Delavier-Klutchko \& Flavin, 1965). In contrast to reports on the latter two bacterial organisms the methionine-cysteine pathway is reversible in various fungi (Delavier-Klutchko \& Flavin, 1965). The possible reversibility of this pathway in $P$. mirabilis has not been investigated but in the light of the above-mentioned reports on $E$. coli and $S$. typhimurium the growth response of cysteine, homoserine and serine requiring mutants to methionine does not provide any proof in this respect.

The quantitative estimates of $S$-methylcysteine (SMC) in methionineless auxotrophs of Proteus mirabilis and Escherichia coli are in agreement with the growth responses of these strains to SMC. The metF mutants of $E$. coli which do not grow with SMC accumulate it in large quantities. The met $\mathrm{F}$ mutants of $P$. mirabilis which do grow with SMC contain negligible amounts of this amino acid. This difference in the met $\mathrm{F}$ metabolic blocks of $P$. mirabilis and $E$. coli cannot be explained. Previous reports of the occurrence of SMC in micro-organisms have been confined to $N$. crassa and yeasts. SMC and its sulphoxide occur in the non-protein nitrogen fraction of various plants (Morris \& Thompson, 1955; Synge \& Wood, 1956; Thompson, Morris \& Zacharius, 1956). Bolton, Cowie \& Sands (1952) did not detect it in E. coli strain B, 
nor did they find homocysteine and cystathionine, although this may be due to the severity of the hydrolytic techniques used. In the present investigation the organisms were not hydrolysed and only free amino acids were examined.

The inability of auxotrophs to accumulate precursors of metabolic blocks has not been reported for other amino acid synthetic pathways in micro-organisms. The existence of more than one pathway leading to the same end-product may possibly influence the accumulation of intermediates in metabolic routes, although this has not been reported. The present findings support the hypothesis that methionine may be synthesized by more than one pathway. Ragland \& Liverman (1956) suggested that methionine was synthesized alternatively by the transthiomethylation of the thiomethyl group of SMC to homoserine. According to Wolff et al. (1956) SMC is synthesized from serine and methanethiol in yeasts. The restricted growth of the homoserine-requiring methionineless mutant of Proteus mirabilis (hser/met-1430) when supplemented with SMC in minimal medium supports these findings since this amino acid is a precursor of methionine in the pathway via SMC. The ability of $m e t \mathrm{~F}, m e t \mathrm{E}$ and $m e t \mathrm{~A} / \mathrm{B}$ mutants of $P$. mirabilis to grow with $\mathrm{SMC}$ also supports the participation of SMC in the formation of methionine via a route which excludes cysteine (see Fig. 1). These results agree with the findings of Wiebers \& Garner (1964) who encountered a cystathionineless mutant of Neurospora crassa which responded to SMC.

Maw (1961) reported the ability of $S$-methylcysteine (SMC) to annul the inhibition of yeast growth by L-ethionine. This methionine analogue is a competitive antagonist of methionine in reactions subsequent to the synthesis of the latter, e.g. incorporation into protein (Gross \& Tarver, 1955) and conversion to $S$-adenosylmethionine (Parks, 1958). According to Maw (1961) the apparent absence of SMC from proteins argues against the possibility that it may annul the action of ethionine by substituting for methionine in one or more reactions essential for growth which have been blocked by ethionine. It is also doubtful whether SMC is an intermediate in the major metabolic reactions of methionine, such as protein synthesis and $S$-adenosylmethionine formation. Maw (1961) concluded that the most tenable explanation is that SMC gives rise to methionine by a separate pathway unaffected by ethionine. Even if SMC participates in the synthesis of methionine by an alternative route, the formation of methionine remains obscure since Wiebers \& Garner (1964) presented data which indicate that neither SMC nor cystathionine are obligate precursors for methionine in Neurospora crassa. They proposed that SMC and cystathionine contribute to sulphur metabolism in general as alternative sources of reduced sulphur, or function as regulatory compounds. The fact that conventional methionineless auxotrophs can be isolated suggests that methionine synthesis by an alternative route does not satisfy the requirements of the organism except when exogenous SMC is present. This may mean that methionine synthesis via SMC is in turn dependent on the synthesis of methionine by the classical pathway or on the presence of methionine or a source of methyl groups. The role of SMC in the synthesis of methionine by $P$. mirabilis and $E$. coli is at present being investigated. This may yield information to explain the failure of methionine auxotrophs of $P$. mirabilis to accumulate precursors of metabolic blocks.

This investigation was supported by grants from the South African Council for Scientific and Industrial Research to Professor J. N. Coetzee. 


\section{REFERENCES}

Bolton, E. T., Cowie, D. B. \& SANDS, M. K. (1952). Sulfur metabolism in Escherichia coli. III. The metabolic fate of sulfate sulfur. J. Bact. 63, 309.

Cauthen, S. E., Foster, M. A. \& Woods, D. D. (1966). Methionine synthesis by extracts of Salmonella typhimurium. Biochem. J. 98, 630.

Coetzee, J. N. (1965). Arginineless auxotrophs of Proteus. Med. Proc. 11, 250.

Coktzee, J. N. \& SACks, T. G. (1960). Transduction of streptomycin resistance in Proteus mirabilis. J. gen. Microbiol. 23, 445.

Clowes, R. C. (1958). Nutritional studies of cysteineless mutants of Salmonella typhimurium. J. gen. Microbiol. 18, 140.

Cowie, D. B., Bolton, E. T. \& Sands, M. K. (1950). Sulfur metabolism in Escherichia coli. I. Sulfate metabolism of normal and mutant cells. J. Bact. 60, 233.

DAvIS, B. D. (1948). Isolation of biochemically deficient mutants of bacteria by penicillin. J. Am. chem. Soc. $70,4267$.

Davis, B. D. \& Mingioli, E. S. (1950). Mutants of Escherichia coli requiring methionine or vitamin B 12. J. Bact. 60, 17.

Delavier-Klutchko, C. \& Flavin, M. (1965). Enzymatic synthesis and cleavage of cystathionine in fungi and bacteria. J. biol. Chem. 240, 2537.

Demerec, M., Bertani, G. \& Flint, J. (1951). A survey of chemicals for mutagenic action on Escherichia coli. Am. Nat. 85, 119.

Demerec, M., Hartman, P. E., Moser, H., Kanazir, D., Demerec, Z. E., Fitzgerald, P. L., Glover, S. W., Lahr, E. L., Westover, W. E. \& YuRA, T. (1955). Bacterial genetics. I. Yb. Carnegie Instn Wash. 54, 219.

Gorini, L. \& KaUfman, H. (1960). Selecting bacterial mutants by the penicillin method. Science, N.Y. 131, 604.

Gornall, A. G., Bardawill, C. J. \& David, M. M. (1949). Determination of serum proteins by means of the biuret reaction. J. biol. Chem. 177, 751 .

Gross, D. \& TARVER, H. (1955). The incorporation of ethionine into the proteins of Tetrahymena. J. biol. Chem. 217, 169.

Horowrrz, N. H. (1955). Symposium on Amino Acid Metabolism. Discussion, p. 631. Baltimore: The Johns Hopkins Press.

LAMPEN, J. O., ROEPKe, R. R. \& Jones, M. J. (1947). Studies on the sulfur metabolism of Escherichia coli. III. Mutant strains of Escherichia coli unable to utilize sulfate for their complete sulfur requirements. Archs Biochem. 13, 55.

LEDERBERG, J. (1946). Studies in bacterial genetics. J. Bact. 52, 503.

Lederberg, J. \& LeDerberg, E. M. (1952). Replica plating and indirect selection of bacterial mutants. J. Bact. 63, 399.

LEDERBERG, J. \& ZINDER, N. (1948). Concentration of biochemical mutants of bacteria with penicillin. J. Am. chem. Soc. 70, 4267.

Leggett Bailey, J. (1962). Techniques in Protein Chemistry. London: Elsevier Publishing Company.

MAW, G. A. (1961). Ability of $S$-methyl-L-cysteine to annul the inhibition of yeast growth by L-ethionine and by $S$-ethyl-L-cysteine. J. gen. Microbiol. 25, 441.

Meister, A. (1965). Biochemistry of the Amino Acids, 2nd ed. London: Academic Press.

MOORE, S. (1963). On the determination of cysteine as cysteic acid. J. biol. Chem. $238,235$.

MorRIs, C. J. \& Thompson, J. F. (1955). Isolation of $L(+)-S$-methylcysteine sulphoxide from turnip roots. Chemy Ind. p. 951.

Parks, L. W. (1958). S-Adenosylethionine and ethionine inhibition. J. biol. Chem. $232,169$.

Postgate, J. R. (1963). The examination of sulphur auxotrophs: a warning. J. gen. Microbiol. 30, 481.

RAGLAND, J. B. \& LIVERMAN, J. L. (1956). $S$-methyl-L-cysteine as a naturally occurring metabolite, in Neurospora crassa. Archs Biochem. Biophys. 65, 574.

RANDERATH, K. (1964). Thin Layer Chromatography (trans. D. D. Libman), p. 93. London: Academic Press Inc.

Roberts, R. B., Abelson, P. H., Cowie, S. B., Bottom, E. T. \& Britren, R. J. (1955). Studies of biosynthesis in Escherichia coli. Chap. 18. Sulfur metabolism. Publs Carnegie Instn 607, 318.

ROWBURY, R. J. (1964). The accumulation of $O$-succinylhomoserine by Escherichia coli and Salmonella typhimurium. J. gen. Microbiol. 37, 171.

Sanderson, K. E. \& Demerec, M. (1965). The linkage map of Salmonella typhimurium. Genetics 51, 897.

SMттн, D. A. (1961). Some aspects of the genetics of methionineless mutants of Salmonella typhimurium. J. gen. Microbiol. 24, 335. 
SYNGE, R. L. M. \& WoOD, J. C. (1956). (+)S-methyl-L-cysteine sulphoxide in cabbage. Biochem. $J$. 64, 252.

Thompson, J. F., Morris, C. J. \& Zacharius, R. M. (1956). Isolation of (-)S-methyl-L-cysteine from beans (Phaseolus vulgaris). Nature, Lond. 178, 593.

Wiebers, J. L. \& GARneR, H. R. (1963). Isolation of homoserine and serine sulfhydrase from Neurospora crassa. Abstr. 145th Meeting Am. chem. Soc. p. $22 \mathrm{C}$.

Wiebers, J. L. \& GARNER, H. R. (1964). Use of $S$-methylcysteine and cystathionine by methionineless Neurospora mutants. J. Bact. 88, 1798.

Wolff, E. C., Black, S. \& Downey, P. F. (1956). Enzymatic synthesis of S-methylcysteine. J. Am. chem. Soc. $78,5958$. 